\title{
REVIEW
}

\section{Semen analysis and sperm function testing}

\author{
Daniel R Franken ${ }^{1}$ and Sergio Oehninger ${ }^{2}$
}

Despite controversy regarding the clinical value of semen analysis, male fertility investigation still relies on a standardized analysis of the semen parameters. This is especially true for infertility clinics in both developing and developed countries. Other optional tests or sophisticated technologies have not been widely applied. The current review addresses important changes in the analysis of semen as described in the new World Health Organization (WHO) manual for semen analysis. The most important change in the manual is the use of evidence-based publications as references to determine cutoff values for normality. Apart from the above mentioned changes, the initial evaluation and handling methods remain, in most instances, the same as in previous editions. Furthermore, the review evaluates the importance of quality control in andrology with emphasis on the evaluation of sperm morphology. WHO sperm morphology training programmes for Sub-Saharan countries were initiated at Tygerberg Hospital in 1995. The external quality control programme has ensured that the majority of participants have maintained their morphological reading skills acquired during initial training. This review reports on current sperm functional tests, such as the induced acrosome reaction, and sperm-zona pellucida binding assays, as well as the impact of sperm quality in terms of DNA integrity, and the relationship of sperm function tests to sperm morphology. Asian Journal of Andrology (2012) 14, 6-13; doi:10.1038/aja.2011.58; published online 19 December 2011

Keywords: male infertility; quality assurance; semen analysis; spermatozoa; sperm concentration; sperm function; sperm morphology; sperm motility

\section{INTRODUCTION}

Although the clinical value of the analysis of human semen has previously been questioned, ${ }^{1,2}$ it has lately regained its position as the cornerstone of the male work-up schedule. ${ }^{3}$ It is accepted that every male infertility work-up should start with the basics, namely, a thorough history, physical examination and at least two semen analyses. ${ }^{4}$ The new World Health Organization (WHO) manual for the examination and processing of human semen is a great improvement on the previous editions. The addition of sperm cryopreservation techniques, the expansion of the section on sperm preparation and the inclusion of new appendices have contributed to the production of a user-friendly laboratory manual. The most important change in the manual is the use of evidence-based publications as references to determine cutoff values for normality. Apart from these changes, the initial evaluation and handling methods remain in most instances the same as in the fourth edition of the manual, ${ }^{5}$ i.e., sample collection, initial macroscopic examination and initial microscopic investigation.

\section{THE SEMEN ANALYSIS (WHO 2010)}

The methods for the evaluation of human semen as described in the older WHO manuals ${ }^{5-7}$ are widely used as a standard reference for laboratories involved with semen analyses. However, these previous manuals lacked clearly defined reference or normal values since the data were accumulated from imprecisely defined normal reference populations. Furthermore, the data were obtained from laboratories that used incomparable analytical methodologies. These so-called reference values caused confusion among clinicians because although they were based on information of semen variables of men who had become recent fathers, they did not include true reference ranges or limits. Moreover, owing to the lack of consensus among centres, some authors regarded these values for sperm concentration, morphology and motility as either too low or too high. Centres that considered values for concentration, morphology and motility too high found a group of fertile men classified as subfertile. ${ }^{8-11}$ On the other hand, fertile men may also be investigated for infertility and subsequently treated as a result of their low semen quality. ${ }^{12,13}$

To establish evidence-based reference values, the WHO 2010 manual describes the values obtained in eight countries from 1953 men who became fathers with a time to pregnancy of less than 12 months. Therefore, this is a population of fertile men whose spouses were of high or normal fecundity and who established a pregnancy in $\leqslant 12$ months. ${ }^{14}$ Nonetheless, there is still scepticism about certain aspects of the new WHO manual. ${ }^{15}$ The criticism by Eliasson ${ }^{15}$ is mainly aimed at the recommendations for the evaluation of progressive motility and sperm morphology. According to Eliasson, ${ }^{15}$ these recommendations are not evidence-based, which is true regarding progressive motility, but this assertion is unfounded for sperm morphology evaluation. ${ }^{4}$ Recent publications comparing sperm morphology cutoff values with in vitro and in vivo pregnancy results in infertile populations or socalled fertile and subfertile populations are in close agreement with the WHO 2010 values. $^{16,17}$

Abandoning the distinction between fast- and slow-progressing spermatozoa may well be regarded as a backward step. ${ }^{15,18}$ However, our experience indicates that the technician's ability to distinguish

${ }^{1}$ Department of Obstetrics and Gynaecology, Tygerberg Hospita, Tygerberg, Cape Town 7505, South Africa and ${ }^{2}$ Department of Obstetrics and Gynaecology, Eastern Virginia Medical School, Jones Institute for Reproductive Medicine, Norfolk, VA 23507, USA

Correspondence: Professor DR Franken (drf@sun.ac.za)

Received: 25 May 2011; Revised: 26 August 2011; Accepted: 17 November 2011; Published online: 19 December 2011 
between fast- (previously grade a) and slow- (previously grade b) moving spermatozoa is poor, making internal and external quality control difficult. The decision to reject categorizing progressive spermatozoa into fast and slow in the WHO 2010 manual was also based on the inability of technicians to gauge velocities accurately and the manual suggests that if velocities need to be known, a computer assisted sperm analyser system should be employed. ${ }^{19}$

\section{The wet preparation}

The wet preparation, i.e., a preparation made with undiluted semen from a specific semen volume and cover slip area, forms an important part of the semen analysis. The wet preparation is used to determine the dilution of semen required to allow accurate measurement of the sperm concentration.

\section{Assessment of motility}

A major change in the new WHO manual is in the evaluation and categorisation of sperm motility. It is now recommended that spermatozoa should be categorized as progressively motile, non-progressively motile and immotile (instead of grade a, b, c or d). Technicians often found this method difficult to define the forward progression so accurately without bias. ${ }^{20}$ The WHO 2010 manual, however, recommends the use of a simple system for grading motility which distinguishes spermatozoa with progressive or non-progressive motility from those that are immotile. The motility of each spermatozoon is graded as follows:

- progressive motility (PR): spermatozoa moving actively, either linearly or in a large circle, regardless of speed;

- non-progressive motility (NP): all other patterns of motility with an absence of progression, i.e., swimming in small circles, the flagellar force hardly displacing the head, or when only a flagellar beat can be observed;

- immotility (IM): no movement.

When reporting sperm motility, it is advised to specify total motility $(\mathrm{PR}+\mathrm{NP})$ or progressive motility $(\mathrm{PR})$. It is well recognized that the percentage of progressively motile sperm is associated with pregnancy rates ${ }^{16,21,22}$ and great care should be taken to ensure accurate measurements.

\section{Assessment of sperm concentration}

The improved Neubauer haemacytometer that has two counting chambers is recommended for determining sperm concentration. Other counting chambers, i.e., disposable chambers, shallow chambers that fill by capillary action or the deep haemacytometer, will need different calculation factors. It may be possible to correct for these, ${ }^{23,24}$ but it is not advised. ${ }^{25}$ The terms 'total sperm number' and 'sperm concentration' describe different concepts. Sperm concentration refers to the number of spermatozoa per unit volume of semen and is a function of the number of spermatozoa emitted and the volume of fluid diluting them. Total sperm number refers to the total number of spermatozoa in the entire ejaculate and is obtained by multiplying the sperm concentration by the semen volume. ${ }^{4}$ The total sperm number per ejaculate is recommended as a parameter that provides information on testicular capacity to produce spermatozoa. Although the total motile sperm count and progressive motility present in the inseminate at the time of intrauterine insemination (with washed semen) is a major determinant for pregnancy outcome in this scenario, the value of these parameters for natural conception is still debatable. ${ }^{26}$
Another important aspect that deserves further attention relates to the concept of detection limits of concentration measurements and the use of the term 'azoospermia'. In today's environment, in cases of obstructive and non-obstructive azoospermia, the presence of any viable/motile spermatozoa in the centrifuged samples becomes critical to the decision whether to offer intracytoplasmic sperm injection (ICSI) or testicular sperm aspiration ICSI. When an accurate assessment of low sperm numbers without centrifugation is required, the Neubauer chamber can be filled with $1+1(1: 2)$ diluted semen. This procedure can theoretically detect a concentration of 250000 spermatozoa per millilitre with a sampling error of $20 \%{ }^{4}$

\section{Assessment of sperm morphology}

The assessment of normal forms of spermatozoa is the basis of morphology criteria set by the WHO. Evidence to support the relationship between the percentage of 'normal' forms, as defined by strict categorisation with fertilisation rates in vivo $o^{27,28}$ and in vivo ${ }^{29,30}$ justifies the approach.

The descriptions for normal spermatozoa require that all 'borderline' forms be considered abnormal. They also included spermatozoa adhering to the following criteria: (i) in principle the head is oval shaped with a smooth contour; and (ii) allowing for slight shrinkage that fixation induces, the head should be $4-5 \mu \mathrm{m}$ in length and $2.5-$ $3 \mu \mathrm{m}$ in width. The total length-to-width ratio should be $1.5-1.75$. Additionally, there should be a well-defined acrosomal region comprising $40 \%-70 \%$ of the head area. The mid-piece should be slender, less than $1 \mu \mathrm{m}$ in width, about one and a half times the length of the head, and attached axially to the head. The tail should be straight, uniform, and thinner than the mid-piece, uncoiled and approximately $45 \mu \mathrm{m}$ long. ${ }^{28}$

A normal sperm head can be defined as normal oval shaped with a smooth contour. Cases that are also considered as normal include sperm heads that are slightly tapered in the posterior region or spermatozoa with a slightly narrower heads and also forms with a slightly narrower heads combined with a slightly tapered (width $\times$ length $=4 \times 2.5 \mu \mathrm{m}$, slightly tapered) post-acrosomal region. These minor variations of spermatozoa represent the forms that are considered normal. Borderline forms or slightly amorphous heads are those forms with configurations that fall outside the range of normal variation. ${ }^{28}$ The different types of normal and abnormal sperm are represented with excellent micrographs in the WHO 2010 manual. Strict morphology therefore allows the classification of normality and of spermatozoa with head configurations that fall outside the range provided of normal cells (oval shaped), but in which the abnormality is not pronounced enough to be classified as abnormal.

\section{Abnormal spermatozoa. The following categories of defects are important: ${ }^{28}$}

Head defects, namely, large, small, tapered, pyriform, round and amorphous heads, vacuolated heads $(>20 \%$ of the head area occupied by unstained vacuolar areas), heads with small acrosomal area $(<40 \%$ of head area) and double heads, or any combination of these.

Neck and mid-piece defects, include 'bent' neck (the neck and tail form an angle of greater than $90^{\circ}$ to the long axis of the head), asymmetrical insertion of the mid-piece into the head, thick or irregular mid-piece, abnormally thin mid-piece (i.e., no mitochondrial sheath) or any combination of these.

Tail defects, include short, multiple, hairpin, broken tails, bent tails $\left(>90^{\circ}\right)$, tails of irregular width, coded tails or any combination of these. 


\section{Quality assurance in semen analysis}

Quality assurance (QA) is an integral part of any laboratory. Furthermore, proficiency testing, i.e., internal and external QA, should be routinely performed to ensure reliable clinical results. Owing to the robust manner in which semen analysis is performed, Jequier $^{31}$ questioned the need for QA since she considered it no longer necessary to perform an accurate semen analysis because there is no evidence that it has any real clinical value. ${ }^{31}$ However, it has been shown that the techniques of semen analysis are often still poorly implemented at many locations. ${ }^{32}$ Nonetheless, following the introduction of QA into the andrology laboratories, the data subsequently generated have led to a growing number of studies showing that the results of semen analysis correlate well with natural conception and some assisted reproductive technologies.

The evaluation of the essential sperm characteristics (concentration, morphology and motility) can be improved by introducing international standardisation for the entire sperm morphology evaluation procedure, mandatory international training and the installation of international external quality control (EQC) schemes. The WHO's Human Reproductive Programme in conjunction with the Department of Obstetrics and Gynaecology has presented training workshops for Sub-Saharan African countries at Tygerberg Hospital since 1997 with satisfying results. In general, the results have indicated a great lack of knowledge especially about sperm morphology evaluation. However, once trained, the workshop participants showed a statistically significant improvement in their evaluation. ${ }^{33-35}$

Our experience has repeatedly indicated the important role of training of andrology technologists in providing clinically relevant results. ${ }^{33,35,36}$ Once trained, the technologist needs his technical reading skills monitored by an EQC programme. ${ }^{33}$

Clinicians, especially in developing countries, where diagnostic andrology facilities are not readily available, still rely on the results of the semen analysis, in order to reach a diagnosis. QA should, therefore, be a fundamental part of the andrology laboratory. Internal and external QA (proficiency testing) consequently should form an important part of the daily activities of the laboratory. However, although there may have been some improvements in the training of laboratory scientists, recent studies have shown that the techniques of semen analysis are still poorly implemented at many locations. ${ }^{36-39}$

EQC programme. Owing to an increasing demand for infertility treatment in developing countries, the andrology unit of Tygerberg Hospital, in conjunction with the WHO's Human Reproductive Programme, initiated annual seminology workshops in 1995. To date, this programme has trained 135 individuals from 17 countries in the subSaharan and eastern Mediterranean regions. The training programme was followed up by an EQC programme for morphology. The studies received the approval of the Institutional Review Board at the University of Stellenbosch. Every 3 months, participants received Papanicolaou stained slides bearing spermatozoa from normal (>14\%, normal pattern), terato- (5\%-14\%, G-pattern) or severely teratozoospermic ( $\leqslant 4 \%$, P-pattern) semen smears.

Because these morphological slides for evaluation of trainees were randomly selected sperm smears from different individuals each containing varying numbers of normal spermatozoa, standardisation was needed in respect of an index that was independent of the morphological level. Let $P$ denote the morphology score (\%) for a slide. The standard deviation (s.d.) of this result is $\sqrt{P(100-P)}$, which shows the dependence of the variance on the number of spermatozoa counted. From the assumption that the Tygerberg morphology reading is the gold standard, the index is the following score:

$$
\text { s.d. score }=\frac{\text { Trainee score }- \text { Tygerberg score }}{\text { s.d. Tygerberg score }}
$$

This is the equivalent of the $Z$-scores used for normally distributed data. The s.d. decreases with lower percentages of normal morphology. The score reflects the number of s.d. units of the gold standard by which the measurement of the trainee differs from the gold standard by which for the specific slide. ${ }^{40,41}$

Each trainee can be evaluated on the s.d. score for his level of agreement with the gold standard. The s.d. score levels chosen for this purpose were $-0.2-0.2$ (dotted lines, Figure 1), which correspond roughly with the 25 th and 75 th percentiles of the s.d. scores after the training.

The median s.d. score for the 42 participants who had an initial evaluation before training was 0.88 which is significantly different from $0(P<0.0001)$ and indicates that the group as a whole substantially overestimated their normal morphology forms before training. The median of the 61 evaluations immediately after training was 0.025 which is not significantly different from $0(P=0.7659)$. This indicates that the group as a whole had come closer to the gold standard in their readings. From Figure 1, it is also evident that some individuals did not meet the gold standard (reference value) after training, but on the whole the group, maintained the standard after training (Figure 1).

The training programme has ensured that the majority of the participants have maintained their morphological reading skills and comply with the gold standard as set by Tygerberg Hospital. The s.d. limits of 0.2 are not excessively strict. Very few individuals were completely 'off the mark' and some remedial action could be taken. From the individual profiles, it is also evident that the participant must be allowed some leeway since many of them had initial problems but then improved. The s.d. limits of 0.2 are ad hoc but seem to be close to the standards attainable in this programme. It provides a simple tool for the convenor and can also be used as feedback to the participant regarding consistent under- or overestimation of normal morphology.

\section{Assessment of sperm concentration and progressive motility}

Figure 2 depicts the Box-Whisker plots (mean \pm s.d.) of before and after training of Sub-Sahara technologists recorded during WHO seminology workshops at Tygerberg Hospital. The results for sperm concentration indicated a significant difference $(P=0.001)$ before and after training. However, the results for progressive motility did not differ ( $P=0.0 .6)$ between the training sessions.

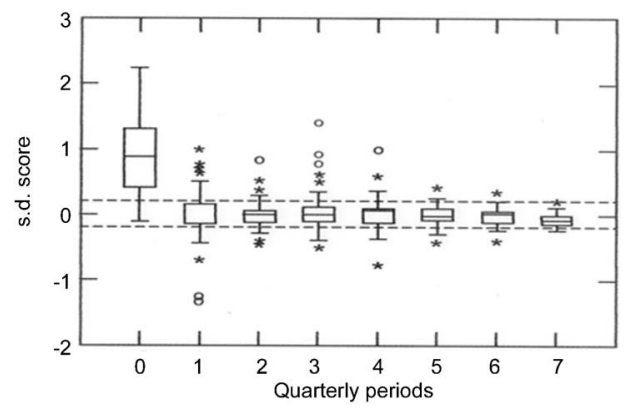

Figure 1 The mean descriptive values of the s.d.-scores of 42 technologists from 19 laboratories at the various time points graphically depicted. 

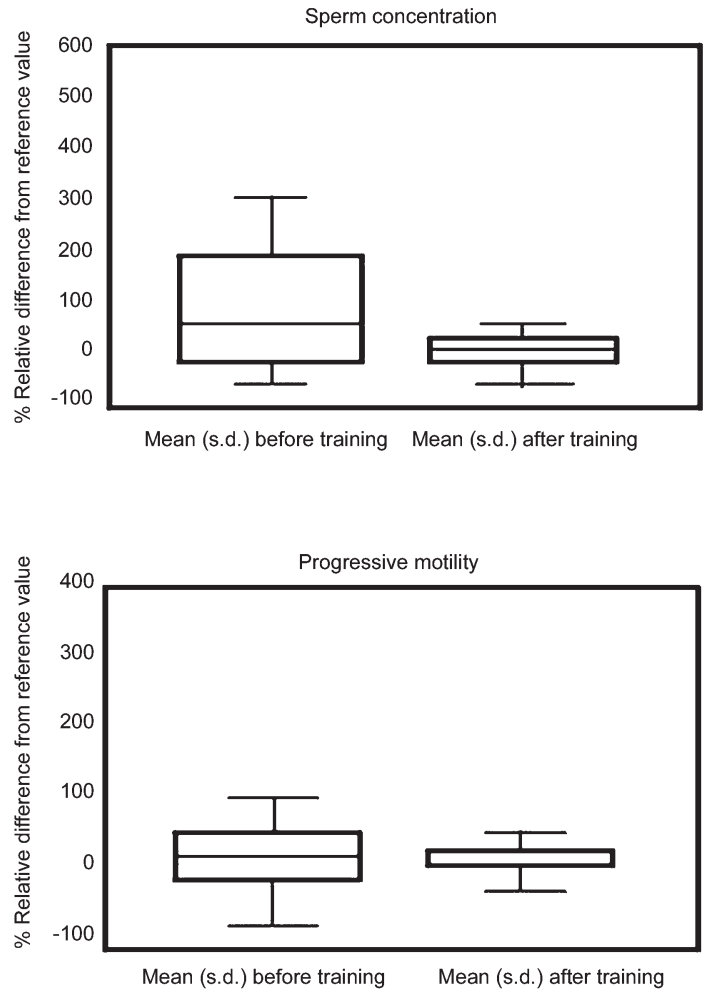

Figure 2 Box Whisker Plots recorded during pre- and post-training workshops for sperm concentration and motility.

\section{Assessment of vitality}

Sperm membrane integrity can be estimated on samples with a simple inexpensive dye- exclusion test. This is especially important for samples with less than about $40 \%$ progressively motile spermatozoa. It is important to know whether immotile spermatozoa are alive or dead, especially in cases where ICSI is the considered therapy. A one-step staining technique using an eosin-nigrosin suspension is recommended. ${ }^{42}$

\section{Reference limits}

The WHO 2010 manual provides semen values obtained from 1953 fertile men as the reference limits for fertility. The following one-sided lower reference limits, the fifth centiles (with 95\% confidence intervals), were generated from men whose partners had time to pregnancy $<12$ months: semen volume, $1.5 \mathrm{ml}(1.4-1.7 \mathrm{ml})$; total sperm number, 39 million per ejaculate (33-46 million); sperm concentration, 15 million per millilitre (12-16 million); vitality, 58\% live (55\%-63\%); progressive motility, $32 \%(31 \%-34 \%)$; total (progressive and nonprogressive) motility, $40 \%(38 \%-42 \%)$; morphologically normal forms, $4.0 \%(3.0 \%-4.0 \%){ }^{14}$

\section{SPERM FUNCTION TESTING}

Sperm functional testing is best performed in a specialized academic institution, since clinics are generally not equipped with the necessary apparatus or expertise. The only exception might be the hemizona assay, since the oocytes can be bisected with the aid of a stereo microscope and a microsurgical blade to divide the oocyte into two equal halves (hemizonae). It is well recognized that sperm dysfunction is one of the more common causes of male infertility, although major advances in this field have been achieved ${ }^{43,44}$ in the past 20 years, our knowledge of the cellular and biochemical basis for this condition is still limited. Indeed, our understanding of the physiology of the normal human spermatozoon, let alone the dysfunctional one, is lacking.
The ideal sperm function test or battery of tests should permit the following clinical steps: (i) diagnosis of a specific sperm dysfunction; (ii) prediction of fertilisation or pregnancy rates; and (iii) indication of an appropriate therapy to alleviate the identified sperm dysfunction. ${ }^{45}$ Owing to the unavailability of material, appropriate equipment and expertise in some centres, the andrology investigation should focus on a practical diagnostic approach.

A standard routine semen analysis performed by an experienced person should assist the consulting clinician in the therapy of choice, but couples referred to tertiary care centres specialized in andrology testing can be further evaluated by means of sperm function tests. The European Society of Human Reproduction and Embryology ${ }^{46}$ and the WHO have selected induced acrosome reaction and sperm-binding assays as research tests for approaching diagnostic application in the clinic. Results of a meta-analysis of sperm function tests have demonstrated high predictive power of the sperm-zona pellucida binding and the induced acrosome reaction assays for fertilisation outcome. ${ }^{47}$

Observations made in a previous study concluded that sperm morphology is closely correlated with specific sperm functions. ${ }^{48,49}$ Furthermore, Esterhuizen et al. ${ }^{50}$ point out that sperm morphology evaluation, especially the configuration of the acrosome, is a good method to estimate sperm fertilizing ability. Understandably, this relationship is closest if the physiological inducer, zona pellucida, is used to induce acrosome reaction for diagnostic purposes. ${ }^{51}$

Likewise, Menkveld et al. ${ }^{52}$ showed that sperm morphology correlates significantly with the sperm cell's ability to bind to the zona pellucida. ${ }^{53-55}$ Menkveld et al. ${ }^{56}$ concluded that sperm with small acrosomes are more susceptible to cell death and non-physiological acrosomal loss. Acrosome size reflects the physiological capability of sperm function and therefore, male fertility potential.

\section{Morphology and DNA status}

Abnormalities at the level of the sperm nucleus with implications on reproductive outcome include DNA strand breaks, numerical and structural chromosomal abnormalities, Y chromosome microdeletions and alterations in the epigenetic regulation of the paternal genome. Recently, there has been a focus on the analysis of sperm DNA damage, as an indicator of sperm quality. The most common types of identified sperm DNA damage are: (i) single and double DNA strand breaks; (ii) the chemical modification of a base by, for example, oxidation or alkylation; (iii) inter- or intrastrand crosslinkage; and (iv) DNA-protein crosslinks. ${ }^{57,58} \mathrm{~A}$ variety of tests have been introduced including terminal deoxynucleotidyl transferase-mediated dUTP nick end-labelling or TUNEL, ${ }^{59}$ comet, ${ }^{60}$ in situ nick translation, ${ }^{61}$ DNA breakage detection-fluorescence in situ hybridisation, ${ }^{62}$ sperm chromatin dispersion test ${ }^{63}$ and sperm chromatin structure assay. ${ }^{64}$ Some of these tests measure DNA damage directly, such as TUNEL, or comet at neutral $\mathrm{pH}$; others measure DNA damage after denaturation steps, such as the sperm chromatin structure assay, sperm chromatin dispersion and comet at acid or alkaline $\mathrm{pH}^{65}$ Indirect methods measure DNA susceptibility to denaturation after exposure to acid conditions. ${ }^{66}$

ICSI has dramatically modified the treatment approach to male infertility. During ICSI, only morphologically normal and motile spermatozoa are typically used to fertilize an oocyte. Unlike its strong predictive value for conventional in vitro fertilisation (IVF), sperm morphology assessed by strict categorisation has little prognostic value in ICSI cycle outcomes, and the standard microscopic selection of spermatozoa with 'normal' morphology during the ICSI procedure allows excellent outcomes even in samples with severe teratozoospermia. ${ }^{67}$ Although there 
are positive correlations between the degrees and types of teratozoospemia and sperm chromosomal anomalies or DNA damage, sperm morphology per se is not a strong predictor of aneuploidies or DNA fragmentation. ${ }^{68}$

It has recently been reported in infertile men that spermatozoa with apparently normal morphology may have DNA fragmentation. ${ }^{67,69}$ This finding raised the possibility that spermatozoa with normally shaped heads but with DNA fragmentation could be mistakenly selected for oocyte injection during ICSI. ${ }^{70}$ This concern is clinically significant because the presence of an increased proportion of normal spermatozoa with damaged DNA is negatively associated with embryo quality and also pregnancy outcome after ICSI. A hypothesis has been put forward that the examination of DNA integrity in the subpopulation of highly motile (following swim-up recovery, hence viable) and morphologically normal cells (and not in the total sperm population) should provide better information in predicting ICSI success. To date, it is not possible to assess DNA integrity in the actual spermatozoa to be injected during ICSI, and a variety of sperm separation techniques are only partly efficient in this regard. ${ }^{71}$ We propose that the evaluation of DNA fragmentation in morphologically normal spermatozoa obtained from a separated motile fraction is apparently, the closest, albeit indirectly, way to reflect DNA normality. ${ }^{69,70}$ This can be done through simultaneous assessment of morphology and DNA status with phase contrast and immunofluorescent microscopy, in a relatively fast and technically easy fashion.

\section{Acrosome reaction}

Research over the last decade has added important information on sperm function, such as that sperm morphology correlates significantly with the sperm cell's ability to bind to the zona pellucida. ${ }^{72,73}$ Furthermore, Liu and Baker ${ }^{74}$ and Menkveld et al. ${ }^{75}$ have demonstrated that normal sperm acrosomal morphology correlates significantly with sperm binding to the zona pellucida, while Franken et al. ${ }^{76}$ showed a strong relationship between normal sperm morphology and the inducibility of the acrosome reaction. Determining the ability of the acrosome to react is important in the diagnostic and therapeutic approach to couples undergoing conventional assisted reproductive technology treatment. Depending on the retrieved sperm concentration and motility, the ability to acrosome react in the presence of solubilized zona pellucida will determine the therapeutic choice. When the partner's own zona pellucida are unavailable, the zonae of donated oocytes from failed fertilisation cycles can be used. ${ }^{76}$ The zona-bound sperm on these oocytes can be stripped off by aspirating the oocytes vigorously using a pipette with a $90-\mu \mathrm{m}$ inner diameter. In cases of a poor acrosome reaction, ICSI therapy is advised, since in the absence of the acrosome reaction, zona penetration is not possible. In a previous prospective study, ${ }^{75}$ we evaluated the therapeutic role of the zona-induced acrosome reaction (ZIAR) test among couples with repeated poor or no fertilisation during IVF cycles despite having normal sperm parameters (Table 1).

After obtaining Institutional Review Board approval and patient informed consent, we performed a diagnostic cycle. Overall, 182 metaphase II oocytes were aspirated from 11 patients from $<15 \%$ ZIAR group (Table 1). ${ }^{77}$ On the day of the aspiration, retrieved oocytes from each patient were randomly and in most cases equally divided, and then treated by standard IVF procedure $(n=84)$ and ICSI $(n=98)$ treatment in the same cycle. The fertilisation results of the diagnostic cycle of metaphase II oocytes for IVF or ICSI were $4 \%$ and $68 \%$, respectively $(P \leqslant 0.001)$. Failed fertilisation can be the consequence of oocyte anomalies (intrinsic or ovarian stimulation-derived), sperm defects (in quality or quantity) or technical factors. The present study demonstrated that an impaired ZIAR is an important indicator of dysfunctional spermatozoa among men with normal semen quality.

\section{Sperm-zona pellucida binding assays}

Among the multiple important steps in the fertilisation process, including zona penetration and sperm-egg cross-talk following oolemma fusion, the zona pellucida binding capacity of a given sperm population has been shown to be a crucial event during mammalian fertilisation. Originally, human sperm-oocyte interaction was defined in an assay described by Overstreet and Hembree. ${ }^{78}$ This in vitro assay compared the penetration rate of sperm from infertile and fertile into the human zona pellucida. Although this assay was developed to evaluate zona penetration, the methodology formed the cornerstone of future sperm-oocyte interaction tests. This assay outlined bio-assay conditions and oocyte retrieval procedures used for current spermzona binding tests, namely, the hemizona assay ${ }^{43}$ and a competitive intact zona pellucida-binding test. ${ }^{44}$ Both bioassays have the advantage of providing a functional homologous test for sperm binding to the zona pellucida, comparing populations of fertile and infertile spermatozoa in the same assay. It is well documented that these assays provide important evidence on one of the recognition events leading to fertilisation. ${ }^{47,49,76}$ Significant factors affecting the validity of both these assays include oocyte sources and maturation, inter-assay and intra-assay variability, sperm motility, morphology and acrosomal status. $^{45}$

\section{Hypo-osmotic swelling (HOS) test}

Water permeability is a fundamental biophysical property of all living cells. It is known that one quality of the cell membrane is its ability to allow the selective transport of fluids and molecules through it. Sperm membrane function plays an important role during the fertilisation process and can be evaluated by the HOS test. ${ }^{79}$ The test is based on the ability of live spermatozoon to withstand moderate hypo-osmotic stress. The HOS test is indicated in cases when there are very few or no motile sperm present in the ejaculate. Dead spermatozoa whose

Table 1 The mean ( \pm s.d., range) for semen sperm parameters, acrosome response and in vitro fertilisation (IVF) outcome of 35 couples divided according to the zona-induced acrosome reaction (ZIAR) test results

\begin{tabular}{|c|c|c|c|c|c|c|c|}
\hline ZIAR group & $\begin{array}{l}\text { Mean sperm } \\
\text { concentration } \\
\left(10^{6} \text { cells } \mathrm{ml}^{-1}\right)\end{array}$ & $\begin{array}{l}\text { Morphology } \\
\text { (\% normal) }\end{array}$ & $\begin{array}{l}\text { Motility } \\
\text { (\%) }\end{array}$ & $\mathrm{HZI}$ & ZIAR (\%) & $\begin{array}{l}\text { No. of oocytes } \\
\text { retrieved }\end{array}$ & $\begin{array}{l}\text { Fertilized } \\
\text { (\%) }\end{array}$ \\
\hline $\begin{array}{l}<15 \% \\
(n=20)\end{array}$ & $\begin{array}{l}55.8 \pm 16 \\
(22-100)\end{array}$ & $\begin{array}{l}12.9 \pm 4 \\
(8-19)\end{array}$ & $\begin{array}{l}54.5 \pm 13 \\
(40-70)\end{array}$ & $\begin{array}{l}53 \pm 13 \\
(40-70)\end{array}$ & $\begin{array}{l}3.7 \pm 3^{a} \\
(0-8)\end{array}$ & $\begin{array}{l}8.9 \pm 6 \\
(2-22)\end{array}$ & $\begin{array}{l}10.3 \pm 21^{c} \\
(0-60)\end{array}$ \\
\hline $\begin{array}{l}>15 \% \\
(n=15)\end{array}$ & $\begin{array}{l}66.4 \pm 24 \\
(22-100)\end{array}$ & $\begin{array}{l}12.6 \pm 3 \\
(7-18)\end{array}$ & $\begin{array}{l}64.7 \pm 11 \\
(51-80)\end{array}$ & $\begin{array}{l}67 \pm 12 \\
(49-88)\end{array}$ & $\begin{array}{l}22.2 \pm 3^{b} \\
(16-27)\end{array}$ & $\begin{array}{l}8.2 \pm 4 \\
(4-18)\end{array}$ & $\begin{array}{l}85.2 \pm 11^{d} \\
(60-100)\end{array}$ \\
\hline
\end{tabular}

Fisher's exact $t$-test: a vs. b: $P=0.001$; c vs. $\mathrm{d}: P=0.001$. 
plasma membranes are no longer intact do not swell in hypotonic media. The clinical value of the HOS test has been under scrutiny. Jeyendran et al. reported HOS test results to be highly correlated with those of the hamster zona-free penetration assay. ${ }^{79}$ However, there are opposing reports showing that the test does not have a prognostic value, since the test is associated with a high level of false positive results. ${ }^{80}$ As of today, the HOS test is generally used as additional indicator of sperm vitality and can be utilized in cases diagnosed with immotile cilia syndrome ${ }^{81}$ or severe astenozoospermia.

\section{Reactive oxygen species (ROS)}

With regard to ROS, one has to differentiate where the ROS originate, from external sources such as leukocytes that are present in almost any ejaculate $^{82}$ or from within the spermatozoa themselves, as ROS are physiologically produced in any living cell during respiration. Data obtained by Henkel et al. ${ }^{83}$ suggest that extrinsic ROS generated by leukocytes predominately affect the sperm plasma membrane and its related functions such as motility. ${ }^{84}$ On the other hand, intrinsic ROS cause DNA damage as opposed to extrinsic ROS which cause plasma membrane damage.

Like any other living cell, spermatozoa produce large amounts of their energy aerobically by means of enzymatically controlled mitochondrial oxidative phosphorylation and oxidation of hydrogen. Subsequently, the chemical energy is conserved as ATP. During this process in the electron transfer chain, elementary oxygen $\left(\mathrm{O}_{2}\right)$ is reduced to highly reactive free radicals as intermediate products with water $\left(\mathrm{H}_{2} \mathrm{O}\right)$ as end product. However, because this process to convert oxygen into energy is not perfectly efficient, $1 \%-5 \%$ of the consumed oxygen is converted into free radicals. ${ }^{85}$ Thus, spermatozoa are potent producers of ROS. The male germ cell's ROS production is fuelled by the cytoplasmic glucose-6-phosphate dehydrogenase ${ }^{85-87}$ enzyme which is available in higher than normal amounts in morphologically abnormal spermatozoa exhibiting excess residual cytoplasm, which has been shown to be predictive of failed fertilisation. ${ }^{86}$ Spermatozoa exhibiting poor morphology are deemed to generate excessive amounts of ROS. ${ }^{88,89}$ Since excessively ROS-producing spermatozoa seem to damage their own DNA, this has particularly clinical importance. $^{89}$

de Iuliis and co-workers ${ }^{90,91}$ have produced evidence that human spermatozoa are able to produce the highly reactive superoxide anion. Elevated production of ROS in defective human spermatozoa can also be caused by a disruption of the mitochondrial electron transport in human spermatozoa that produces superoxide production, ${ }^{92}$ which, in turn, is stimulated by an abnormally high content of fatty acids in morphologically abnormal spermatozoa. ${ }^{92}$

\section{DISCUSSION}

The WHO 2010 manual was timely in both updating previous recommendations and providing new evidence-based findings and improved explanations of important concepts. In addition, it has maintained its position as a global guide for best laboratory practice and in preventing the adoption of non-evidence-based approaches.

The fifth WHO manual edition (2010) includes high-quality micrographs of spermatozoa considered normal and borderline, accompanied by explanations as to why each spermatozoon has been classified the way it has. This should assist in training technicians to categorize spermatozoa consistently. Owing to the subjective nature of sperm morphology and motility evaluation, each laboratory should implement a QC and QA programme, based on standardized methods and procedures, to ensure that results are both accurate and precise. QC includes establishing specifications for each aspect of a specific test and taking the necessary corrective action to ensure reliable results. QA, on the other hand, is more expansive and not only includes QC, but involves monitoring the ultimate outcome. QC of semen analysis should therefore consist of internal and external programmes. The internal programme records the variations found within an individual technician (intra-individual) and between technicians within the laboratory (inter-individual). The external QC programme encompasses variations recorded between laboratories.

A practical definition of a sperm function test is one that evaluates one or more of the cellular processes exhibited by spermatozoa from the time of ejaculation to fertilisation. The validation of these tests has been subjected to much controversy and poor methodology. ${ }^{46}$ Sperm function tests are currently regarded in most cases as research tools and are not part of the routine diagnostic schedule of the infertile male. The sequential diagnostic approach to unravel the exact cause of male factor infertility has been questioned by the introduction of ICSI. Assisted reproduction programmes either use ICSI as the first line of approach or as an alternative therapy after repeated failed intrauterine insemination or IVF attempts. ${ }^{93,94}$ This clinical approach is directly due to the additional costs that are involved in sperm functional tests. Genetic and DNA integrity seem to be the most important functional parameters to successful fertilisation and embryo development.

Although a comprehensively performed semen analysis remains the initial choice in the evaluation of male infertility, new developments in semen evaluation continue in search of the accurate diagnosis and management of the infertile male. In conclusion, if sperm morphology is done correctly and with care, and with strict application of the guidelines as outlined in the 2010 WHO manual, sperm morphology measurement still has a very important role to play in the clinical evaluation of male fertility potential. ${ }^{95}$

\section{COMPETING FINANCIAL INTERESTS}

The authors declare no competing financial interests.

\section{ACKNOWLEDGMENTS}

The authors wish to extend gratitude towards Dr R. Menkveld, Dr Wole Akande and Dr Davy Chikamata for their individual contributions to the study.

1 Chong AR, Waiters CA, Weinrelb SA. The neglected laboratory test. The semen analysis. J Androl 1983; 4: 280-2.

2 McDonough P. Editorial comment: has traditional sperm analysis lost its clinical relevance? Fertil Steril 1997; 67: 585-7.

3 Agarwal A. What is the future of the sperm analysis. J Clin Embryol 2009; 12: 3-4.

4 World Health Organization. WHO Laboratory Manual for the Examination and Processing of Human Semen. 5th ed. Geneva: World Health Organization; 2010.

5 World Health Organization. WHO Laboratory Manual for Examination of Human Semen and Semen-Cervical Mucus Interaction. 4th ed. Cambridge: Cambridge University Press; 1999.

6 World Health Organization. World Health Organization Laboratory Manual for the Examination of Human Semen and Semen-Cervical Mucus Interaction. 2nd ed. Cambridge: Cambridge University Press; 1987.

7 World Health Organization. World Health Organization Laboratory Manual for the Examination of Human Semen and Semen-Cervical Mucus Interaction. 3rd ed. Cambridge: Cambridge University Press; 1992.

8 Barratt CL, Dunphy BC, Thomas EJ, Cooke ID. Semen characteristics of 49 fertile males. Andrologia 1988; 20: 264-9.

9 Chia SE, Tay SK, Lim ST. What constitutes a normal seminal analysis? Semen parameters of 243 fertile men. Hum Reprod 1998; 13: 3394-8.

10 Gao J, Gao ES, Yang Q, Walker M, Wu JQ et al. Semen quality in a residential, geographic and age representative sample of healthy Chinese men. Hum Reprod 2007; 22: 477-84.

11 Gao J, Gao ES, Walker M, Yang Q, Wu JQ et al. Reference values of semen parameters for healthy Chinese men. Urol Int 2008; 81: 256-62. 
12 Lemcke B, Behre HM, Nieschlag E. Frequently subnormal semen profiles of normal volunteers recruited over 17 years. Int J Androl 1997; 20: 144-52.

13 Bostofte E, Serup J, Rebbe H. Has the fertility of Danish men declined through the years in terms of semen quality? A comparison of semen qualities between 1952 and 1972. Int J Fertil 1983; 28: 91-95.

14 Cooper TG, Noonan E, von Eckardstein S, Auger J, Baker HW et al. World Health Organization reference values for human semen characteristics. Hum Reprod Update 2009; 16: 231-245.

15 Eliasson R. Semen analysis with regard to sperm number, sperm morphology and functional aspects. Asian J Androl 2010; 12: 26-32.

16 Zinaman MJ, Brown CC, Selevan SG, Clegg ED. Semen quality and human fertility: a prospective study with health couples. J Androl 2000; 21: 145-53.

17 Guzick DS, Overstreet JW, Factor-Ltvak P, Brazil C. Nakajima T et al. Sperm morphology, motility and concentration in fertile and infertile men. N Eng/ J Med 2001 ; 345: 1388-93.

18 Björndahl L. The usefulness and significance of assessing rapidly progressive spermatozoa. Asian J Androl 2010; 12: 33-5.

19 Handelsman DJ, Cooper TG. Afterword to Semen Analysis in 21st Century Medicine special issue in Asian Journal of Andrology. Asian J Androl 2010; 12: 118-23.

20 Cooper TG, Yeung $\mathrm{CH}$. Computer-aided evaluation of assessment of 'grade a' spermatozoa by experienced technicians. Fertil Steril 2006; 85: 220-4.

21 Larson KL, DeJonge CJ, Barnes AM, Jost LK, Evenson DP. Sperm chromatin structure assay parameters as predictors of failed pregnancy following assisted reproductive techniques. Hum Reprod 2000; 15: 1717-22.

22 Jouannet P, Ducot B, Spira A. Male factors and the likelihood of pregnancy in infertile couples. I. Study of sperm characteristics. Int J Androl 1988; 11: 379-94.

23 Douglas-Hamilton DH, Smith NG, Kuster CE, Vermeiden JP, Althouse GC. Particle distribution in low-volume capillary-loaded chambers. J Androl 2005; 26: 107-14.

24 Douglas-Hamilton DH, Smith NG, Kuster CE, Vermeiden JP, Althouse GC. Capillaryloaded particle fluid dynamics: effect on estimation of sperm concentration. J Androl 2005; 26: 115-22.

25 Bjorndahl L, Barratt CL. Semen analysis: setting standards for the measurement of sperm numbers. J Androl 2005; 26: 11.

26 Duran HE, Morshedi M, Kruger T, Oehninger S. Intrauterine insemination: a systematic review on determinants of success. Hum Reprod Update 2002; 8: $373-$ 84.

27 Kruger TF, Menkveld R, Stander FS, Lombard CJ, van der Merwe JP et al. Sperm morphologic features as a prognostic factor in in vitro fertilization. Fertil Steril 1986; 46: 1118-23.

28 Menkveld R, Stander FS, Kotze TJ, Kruger TF, van Zyl JH. The evaluation of morphologic characteristics of human spermatozoa according to stricter criteria. Hum Reprod 1990; 5: 586-92.

29 Eggert-Kruse W, Reimann-Anderson J, Rohr G, Pohl S. Tilgen W et al. Clinical relevance of sperm morphology assessment using strict criteria and relationship with sperm-mucus interaction in vivo and in vitro. Fertil Steril 1995: 63: 612-24.

30 van Waart J, Kruger TF, Lombard CJ, Ombelet W. Predictive value of normal sperm morphology in intrauterine insemination (IUI): a structured literature review. Hum Reprod Update 2001; 7: 495-500.

31 Jequier AM. Is quality assurance in semen analysis still really necessary? A clinician's viewpoint. Hum Reprod 2005; 20: 2039-42.

32 Riddell D, Pacey A, Whittington K. Lack of compliance by UK andrology laboratories with World Health Organization recommendations for sperm morphology assessment. Hum Reprod 2005; 20: 3441-5

33 Franken DR, Menkveld R, Kruger TF, Sekadde-Kigondu C, Lombard C. Monitoring technologist reading skills in a sperm morphology quality control program. Fertil Steril 2003; 79: 1637-43.

34 Franken DR, Kruger TF. Lessons learned from a sperm morphology quality control programme. Andrologia 2006; 3: 225-9.

35 Franken DR, Dada OA. Does training assist medical laboratory scientists with better evaluation of sperm morphology. Afr J Reprod Health 2007; 11: 3-8.

36 Holt WV. Is quality assurance in semen analysis still really necessary? A spermatologist's viewpoint. Hum Reprod 2005; 20: 2983-6.

37 Castilla JA, Alvarez C, Aguilar J, González-Varea C, Gonzalvo MC et al. Influence of analytical and biological variation on the clinical interpretation of seminal parameters. Hum Reprod 2005; 21: 847-51.

38 Pacey AA. Is quality assurance in semen analysis still really necessary? A view from the andrology laboratory. Hum Reprod 2006; 21: 1105-9.

39 Bjorndahl L, Barratt CL, Fraser LR, Kvist U, Mortimer D. ESHRE basic semen analysis courses 1995-1999: immediate beneficial of standardized training. Hum Reprod 2002; 17: 1299-305.

40 Franken DR. African experience with sperm morphology training courses. Reprod Med Online 2003; 7: 114-9.

41 Franken DR, Aneck-Hahn N, Kruger TF, Lombaard C. Semenology training programmes: 8 years experience. Fertil Steril 2010; 94: 2615-9.

42 Björndahl L, Söderlund I, Kvist U. Evaluation of the one step eosin nigrosin staining technique for human sperm vitality assessment. Hum Reprod2003; 18: 813-6.

43 Burkman LJ, Coddington CC, Franken DR, Kruger T, Rosenwaks Z et al. The hemizona assay (HZA): development of a diagnostic test for the binding of human spermatozoa to human hemizona pellucida to predict fertilization potential. Fertil Steril 1988; 49: 688-95.

44 Liu DY, Baker HW. Morphology of spermatozoa bound to the zona pellucida of human oocytes that failed to fertilize in vitro. J Reprod Fertil 1992; 94: 71-84.
45 Muller $\mathrm{CH}$. Rationale, interpretation, andrology lab corner validation, and uses of sperm function tests. J Androl 2000; 21: 10-30.

46 ESHRE Andrology Special Interest Group. Consensus Workshop on Advanced Diagnostic Andrology Techniques. Hum Reprod 1996; 11: 1463-79.

47 Oehninger SC, Franken DR, Sayed E, Barroso G, Kolm P. Sperm function and their predictive value fertilization outcome in IVF therapy: a meta analysis. Hum Reprod Update 2000; 6: 160-8.

48 Liu DY, Baker HW. Morphology of spermatozoa bound to the zona pellucida of human oocytes that failed to fertilize in vitro. J Reprod Fertil 1992; 94: 71-84.

49 Liu DY, Baker HW. Relationships between human sperm acrosin, acrosomes, morphology and fertilization in vitro. Hum Reprod 1990; 5: 298-303.

50 Esterhuizen AD, Franken DR, Lourens JG, Prinsloo E, van Rooyen LH. Sperm chromatin packaging as an indicator of in vitro fertilisation rates. Hum Reprod 2000; 15: 657-61.

51 Bastiaan HS, Windt ML, Menkveld R, Kruger TF, Oehninger S et al. Relationship between zona pellucida-induced acrosome reaction, sperm morphology, spermzona pellucida binding, and in vitro fertilization. Fertil Steril 2003; 79: 49-55.

52 Menkveld R, El-Garem Y, Schill WB, Henkel R. Relationship between human sperm morphology and acrosomal function. J Assist Reprod Genet 2003; 20: 432-8.

53 Menkveld R, Franken DR, Kruger TF, Oehninger S, Hodgen GD. Sperm selection capacity of the human zona pellucida. Mol Reprod Dev 1991; 30: 346-52.

54 Liu DY, Baker HW. Morphology of spermatozoa bound to the zona pellucida of human oocytes that failed to fertilize in vitro. J Reprod Fertil 1992; 94: 71-84.

55 Liu DY, Baker HW. The proportion of human sperm with poor morphology but normal intact acrosomes detected with Pisum sativum agglutinin correlates with fertilization in vitro. Fertil Steril 1988; 50: 288-93

56 Menkveld R, Rhemrev JP, Franken DR, Vermeiden JP, Kruger TF. Acrosomal morphology as a novel criterion for male fertility diagnosis: relation with acrosin activity, morphology (strict criteria), and fertilization in vitro. Fertil Steril 1996; 65: 637-44.

57 Aitken RJ, de luliis GN. Origins and consequences of DNA damage in male germ cells. Reprod Biomed Online 2007; 14: 727-33.

58 Aitken RJ, de luliis GN. On the possible origins of DNA damage in human spermatozoa. Mol Hum Reprod 2010; 16: 3-13.

59 Gorczyca W, Traganos F, Jesionowska H, Darzynkiewicz Z. Presence of DNA strand breaks and increased sensitivity of DNA in situ to denaturation in abnormal human sperm cells: analogy to apoptosis of somatic cells. Exp Cell Res 1993; 207: 202-5.

60 Hughes C, Lewis S, McKelvey-Martin V, Thompson W. A comparison of baseline and induced DNA damage in human spermatozoa from fertile and infertile men, using a modified comet assay. Mol Hum Reprod 1996; 2: 613-9.

61 Tomlinson MJ, Moffatt O, Manicardi GC, Bizzaro D, Afnan M et al. Interrelationships between seminal parameters and sperm nuclear DNA damage before and after density gradient centrifugation: implications for assisted conception. Hum Reprod 2001; 16: 2160-5.

62 Fernandez JL, Vazquez-Gundin F, Delgado A, Goyanes VJ, Ramiro-Diaz J, et al. DNA breakage detection-FISH (DBD-FISH) in human spermatozoa: technical variants evidence different structural features. Mutat Res 2005; 453: 77-82.

63 Fernandez JL, Muriel L, Rivero MT, Goyanes V, Vazquez R et al. The sperm chromatin dispersion test: a simple method for the determination of sperm DNA fragmentation. J Androl 2003; 24: 59-66.

64 Evenson DP, Darzynkiewicz Z, Melamed MR. Relation of mammalian sperm chromatin heterogeneity to fertility. Science 1990; 210: 1131-3.

65 Sakkas D, Alvarez JG. Sperm DNA fragmentation: mechanisms of origin, impact on reproductive outcome, and analysis. Fertil Steril 2010; 93: 1027-36.

66 Evenson DP, Wixon R. Comparison of the Halosperm test kit with the sperm chromatin structure assay (SCSA) infertility test in relation to patient diagnosis and prognosis. Fertil Steril 2005; 84: 846-9.

67 French DB, Sabanegh Jr ES, Goldfarb J, Desai N. Does severe teratozoospermia affect blastocyst formation, live birth rate, and other clinical outcome parameters in ICSI cycles? Fertil Steril 2010; 93: 1097-103.

68 Avendaño C, Franchi A, Duran H, Oehninger S. DNA fragmentation of normal spermatozoa negatively impacts embryo quality and intracytoplasmic sperm injection outcome. Fertil Steril 2010; 94: 549-57.

69 Avendaño C, Franchi A, Taylor S, Morshedi M, Bocca S et al. Fragmentation of DNA in orphologically normal human spermatozoa. Fertil Steril 2009; 91: 1077-84.

70 Avendaño C, Oehninger S. DNA fragmentation in morphologically normal spermatozoa: how much should we be concerned in the ICSI era? J Androl 2011; 32: 356-63.

71 Collins JA, Barnhart KT, Schegel PN. Do sperm DNA integrity predict pregnancy with in vitro fertilization? Fertil Steril 2008; 89: 823-31.

72 Menkveld R, Franken DR, Kruger TF, Oehninger S, Hodgen GD. Sperm selection capacity of the human zona pellucida. Mol Reprod Dev 1991; 30: 346-52.

73 Liu DY, Baker HW. Tests of human sperm function and fertilization in vitro. Fertil Steril 1992; 58: 465-83.

74 Liu DY, Baker HW. The proportion of human sperm with poor morphology but normal intact acrosomes detected with Pisum sativum agglutinin correlates with fertilization in vitro. Fertil Steril 1988; 50: 288-93

75 Menkveld R, Rhemrev JP, Franken DR, Vermeiden JP, Kruger TF. Acrosomal morphology as a novel criterion for male fertility diagnosis: Relation with acrosin activity, morphology (strict criteria), and fertilization in vitro. Fertil Steril 1996; 65: 637-44.

76 Franken DR, Bastiaan HS, Kidson A, Wranz P, Habenicht UF. Zona pellucida mediated acrosome reaction and sperm morphology. Andrologia 1997; 29: 311-7. 
77 Franken DR, Esterhuizen A, Oehninger SC. Diagnostic impact of the zona pellucida induced acrosome reaction in an assisted reproductive programme. Embryo Talk 2007; 2 : 3-9

78 Overstreet JW, Hembree WC. Penetration of zona pellucida of non-living human oocytes by human spermatozoa in vitro. Fertil Steril 1976; 27: 815-31.

79 Jeyendran RS, van der Ven HH, Perez-Pelaez M, Crabo BG, Zaneveld LJ. Development of an assay to assess the functional integrity of the human sperm membrane and its relationship to other semen characteristics. J Reprod Fertil 94;70: 219-28.

80 Barratt CL, Osborn R, Harrison PF, Monks N, Dunphy BC et al. The hypo-osmotic swelling test and the sperm mucus penetration test in determining the fertilization of human oocytes. Hum Reprod 1989; 4: 430-4.

81 Peeraer K, Nijs M, Raick D, Ombelet W, Dunphy BC. Pregnancy after ICSI with ejaculated immotile spermatozoa from a patient with immotile cilia syndrome: a case report and review of the literature. Reprod Biomed Online2004; 9: 65963.

82 Wolff H. The biologic significance of white blood cells in semen. Fertil Steril 1995; 63 1143-57.

83 Henkel R, Kierspel E, Stalf T, Mehnert C, Menkveld R et al. Effect of reactive oxygen species produced by spermatozoa and leukocytes on sperm functions in nonleukocytospermic patients. Fertil Steril 2005; 83: 635-42.

84 Chance $\mathrm{B}$, Sies $\mathrm{H}$, Boveris $\mathrm{H}$. Hydroperoxide metabolism in mammalian organs Physiol Rev 1979; 59: 527-605.

85 Gomez E, Buckingham D, Brindle J, Lanzafame F, Irvine DS et al. Development of an image analysis system to monitor the retention of residual cytoplasm by human spermatozoa: correlation with biochemical markers of the cytoplasmic space, oxidative stress and sperm function. J Androl 1996; 17: 276-87.
86 Keating J, Grundy CE, Fivey PS, Elliott M, Robinson J. Investigation of the association between the presence of cytoplasmic residues on the human sperm midpiece and defective sperm function. J Reprod Fertil 1997; 110: 71-7.

87 Aitken RJ, Fisher HM, Fulton N, Gomez E, Knox W et al. Reactive oxygen species generation by human spermatozoa is induced by exogenous NADPH and inhibited by the flavoprotein inhibitors diphenylene iodonium and quinacrine. Mol Reprod Dev 1997; 47: 468-82.

88 Aziz N, Saleh RA, Sharma RK, Lewis-Jones I, Esfandiari N et al. Novel association between sperm reactive oxygen species production, sperm morphological defects, and the sperm deformity index. Fertil Steril 2004; 81: 349-54.

89 Henkel R, Kierspel E, Hajimohammad M, Stalf T, Hoogendijk C et al. DNA fragmentation of spermatozoa and ART. Reprod Biomed Online 2003; 7: 477-84.

90 de luliis GN, Wingate JK, Koppers AJ, McLaughlin EA, Aitken RJ. Definitive evidence for the nonmitochondrial production of superoxide anion by human spermatozoa. J Clin Endocrinol Metab 2006; 91: 1968-75.

91 Koppers AJ, de Iuliis GN, Finnie JM, McLaughlin EA, Aitken RJ. Significance of mitochondrial reactive oxygen species in the generation of oxidative stress in spermatozoa. J Clin Endocrinol Metab 2008; 93: 3199-207.

92 Koppers AJ, Garg ML, Aitken RJ. Stimulation of mitochondrial reactive oxygen species production by unesterified, unsaturated fatty acids in defective human spermatozoa. Free Radic Biol Med 2010; 48: 112-9.

93 Oehninger S. Clinical management of male infertility in assisted reproduction: ICS and beyond. Int J Androl 2011; 34: e319-29.

94 Agarwal A, Monette Bragais FM, Sabanegh E. Assessing sperm function. Urol Clin N Am 2008; 35: 157-71.

95 Menkveld R, Holleboom CA, Rhemrev JP. Measurement and significance of sperm morphology. Asian J Androl 2011; 13: 59-68. 